\title{
Obesity and the lung: 4 - Obesity and asthma
}

\author{
D D Sin, ${ }^{1}$ E R Sutherland ${ }^{2}$
}

${ }^{1}$ The Providence Heart and Lung Institute at St Paul's Hospital, Denver; The James Hogg iCAPTURE Center for Cardiovascular and Pulmonary Research; Department of Medicine (Respiratory Division), The University of British Columbia, Vancouver, BC, Canada; ${ }^{2}$ National Jewish Health, Denver; University of Colorado, Denver, Colorado, USA

Correspondence to:

Dr E R Sutherland, National Jewish Medical and Research Center, 1400 Jackson Street, J201, Denver, CO 80206, USA; sutherlande@njc.org

Received 21 November 2007 Accepted 23 April 2008

\section{ABSTRACT}

Over the past 30 years there has been an epidemic of both obesity and asthma in the western world. A large body of robust epidemiological data has linked obesity with the development and severity of asthma in both children and adults and weight reduction with improvements in asthma severity and symptoms. However, it remains unsettled whether this relationship is causal or confounded by some other factor(s) as mechanistic and physiological studies have produced heterogeneous and at times conflicting findings. This review examines the clinical and epidemiological relationship between obesity and asthma and the purported mechanisms that may link these two processes together.

Globally, there is an epidemic of obesity with more than 1 billion overweight and 300 million obese adults worldwide. ${ }^{1}$ Obesity is also a major problem among children. In the USA alone there are 22 million children under 5 years of age who are overweight and, since 1980, the number of overweight children has doubled while the number of overweight adolescents has more than tripled. ${ }^{1}$ Concurrently, the prevalence of asthma has experienced a similar dramatic increase, with rates being nearly 2.5 times greater today than they were 20 years ago (fig 1). ${ }^{2}$ Whether this association is causal or coincidental remains unsettled, and a major challenge in understanding the nature of the relationship between obesity and asthma has been to determine whether obesity truly modifies asthma risk or phenotype or simply leads to a set of clinical and physiological perturbations that mimic asthma.

In this qualitative review we will critically examine the epidemiological data linking obesity with asthma and the purported mechanisms linking these two conditions. To identify relevant studies for this review, we searched PUBMED using key words "asthma" and "obesity". This review will address a number of specific questions related to the asthma/obesity interaction which are currently being addressed by investigators worldwide, including:

- Does obesity increase the risk of developing asthma?

- If yes, by what mechanism(s)?

- Is the effect of obesity primarily on asthma phenotype as it relates to severity or response to therapy?

- Are the clinical and physiological abnormalities observed in many obese patients truly asthma or simply reflections of mechanical effects of increased body mass on the lungs?

While conclusive answers to these questions remain elusive, an enlarging body of work has begun to shed light on this important problem.

\section{OBESITY AS A MODIFIER OF ASTHMA RISK}

Numerous cross-sectional and case-control studies have shown a significant relationship between obesity and asthma, although there is variability in this literature with regard to how the diagnosis of asthma is ascertained (eg, based on historical data vs physiological characterisation). ${ }^{3-11}$ For instance, in a well performed case-control study from Sweden, Rönmark et al reported that obesity (defined as a body mass index $(B M I) \geqslant 30 \mathrm{~kg} / \mathrm{m}^{2}$ ) increased the odds of asthma (confirmed by bronchoprovocation testing) by 2.7-fold compared with normal body weight (BMI $20-24.9 \mathrm{~kg} / \mathrm{m}^{2}$ ). The odds increased by 2.0 in overweight individuals (BMI 25-29.9 kg/m²), independent of age and sex. ${ }^{12}$ In a similar study, Young et al reported that being overweight increased the risk of asthma (defined by self-report and use of a bronchodilator or corticosteroids) by $40 \%$, and obesity increased the risk by $2-3.8$-fold. ${ }^{11}$ Cross-sectional studies have yielded similar results. For instance, Sin et al, ${ }^{13}$ using data from the Third National Health and Nutrition Examination Survey (NHANES III), demonstrated a dose-dependent relationship between self-report of asthma and BMI, independent of many confounding factors. However, casecontrol or cross-sectional studies are limited in that the directionality of the relationship cannot be determined and they are more susceptible to the introduction of bias.

A more robust method of determining causation in the relationship between obesity and asthma is through longitudinal cohort studies. Table 1 summarises the published longitudinal studies of asthma and obesity. Using data from the Nurses' Health Study, Camargo et a $1^{14}$ prospectively evaluated the relationship between body weight and the incidence of self-reported physician-diagnosed asthma in women. As in the case-control studies, these investigators found a significant relationship between BMI and the incidence of asthma, with obesity increasing the asthma risk by $2.7-3.8$-fold and overweight increasing the risk by $50-70 \%$. More importantly, they showed that participants who reported weight gains of $\geqslant 5 \mathrm{~kg}$ during a 4 year span experienced an increased risk of asthma in a dose-dependent manner. ${ }^{14}$ In the Danish Twin Registry Study, Thomsen et $a l^{15}$ reported that the incidence of new cases of self-reported asthma over 8 years was $4.3 \%$ in Danish adults aged 20-40 years, with a linear relationship between baseline BMI and incident asthma in both men and women. Interestingly, up to a BMI threshold of 31 the risk of asthma was always higher in women than in men, but beyond this threshold the risk of asthma increased exponentially in men but only linearly in women. Nystad et al, ${ }^{16}$ using data from a population-based study of 135000 Norwegians who were 


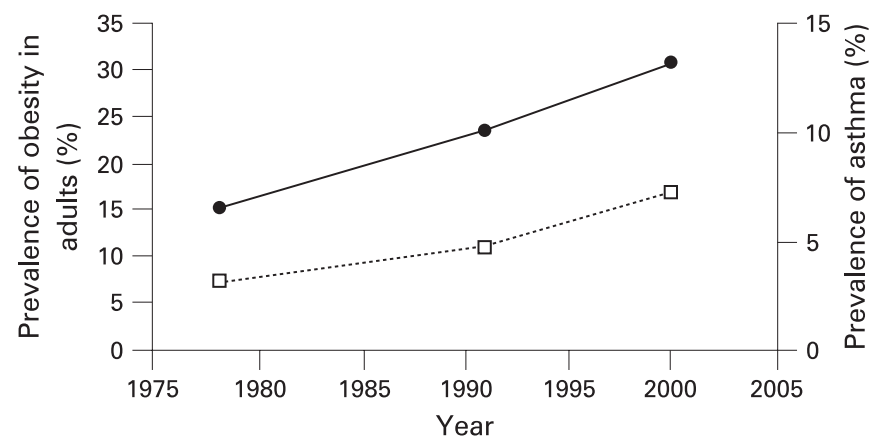

Figure 1 Temporal trends in the prevalence of obesity in adults and asthma in the USA. The dotted line represents the prevalence of asthma ${ }^{2}$ while the solid line represents the prevalence of obesity. ${ }^{67}$

followed for 21 years, found that on average for every one unit increase in BMI above $20 \mathrm{~kg} / \mathrm{m}^{2}$ the risk of self-reported asthma increased by $10 \%$ in men and $7 \%$ in women. In addition to these examples, there have been several other longitudinal studies which have evaluated this relationship. ${ }^{16-21}$ Beuther and Sutherland performed a meta-analysis of these prospective epidemiological studies and reported that, in aggregate, these studies demonstrated a dose-dependent relationship between BMI and the incidence of asthma, ${ }^{22}$ with overweight increasing the odds of incident asthma by $38 \%$ (odds ratio (OR) 1.38 (95\% confidence interval (CI) 1.17 to 1.62)) and obesity increasing the odds by $92 \%$ compared with normal body weight (OR 1.92 (95\% CI 1.43 to 2.59)). In aggregate, while these findings suggest that overweight and obesity do increase the risk of developing asthma, the reliance in many of the cited studies on self-reported rather than physiologically-defined asthma leaves open the possibility that participants are experiencing respiratory symptoms for reasons other than asthma.

\section{ANIMAL MODELS OF THE EFFECT OF OBESITY ON AIRWAY INFLAMMATION AND FUNCTION}

The aforementioned observations from the epidemiological literature suggest a causal relationship between obesity and asthma, but these studies have been unable to shed significant light on potential mechanistic underpinnings. In attempts to evaluate relevant mechanisms, obese mice have been used to describe potential mechanisms by which obesity might modulate airway inflammation and/or function. Commonly studied are genetic models of obesity, including mice with genetic deficiencies in leptin production (ob/ob mouse) or the leptin receptor ( $d b / d b$ mouse), or deficiency in carboxypeptidase $\mathrm{E}$ production ( $C p e^{f a t}$ mouse). In each of these mouse models there is innate enhancement of airway hyper-responsiveness (AHR), as well as ozone or ovalbumin-induced airway inflammation (or sensitisation) and responsiveness that is greater than that observed in lean wild-type controls, suggesting that increased $\mathrm{BMI}$ in humans may predispose to AHR, a cardinal feature of asthma. ${ }^{23-26}$ However, although increased AHR is observed in obese mice, lung inflammation may not be the mechanism by which this occurs. A recent report by Johnston et $a^{23}$ paradoxically showed fewer inflammatory cells (eg, eosinophils and lymphocytes) in the bronchoalveolar lavage fluid following ovalbumin sensitisation in obese compared with lean mice. Ozone exposure, on the other hand, consistently increased lung inflammation more in the obese mice than in the lean animals. ${ }^{24}$ Additionally, adipokines appear to play a prominent role in modulating the risk of asthma in animal models. Whereas leptin augments the inflammatory response in the lungs and increases bronchial responsiveness ${ }^{27}$ adiponectin decreases lung inflammation and reduces bronchial responsiveness in mice. ${ }^{28}$

\section{OBESITY, ATOPY AND AIRWAY INFLAMMATION IN HUMANS}

A number of human studies have assessed the relationship between allergic and/or airway inflammation and obesity, a

Table 1 Selected epidemiological studies of obesity and asthma indicating an increased risk of asthma in obese individuals

\begin{tabular}{|c|c|c|c|c|}
\hline Study & Evaluated population & $\mathbf{n}$ & Time & $\begin{array}{l}\text { Reported OR, RR } \\
\text { BMI }>\mathbf{3 0}\end{array}$ \\
\hline \multirow[t]{2}{*}{ Camargo $^{14}$} & Nurses' Health II & 85911 & 4 years & \\
\hline & Women & 85911 & & $2.7(2.3$ to 3.1$)$ \\
\hline \multirow[t]{2}{*}{ Romieu $^{20}$} & French E3N Cohort & 67229 & 3 years & \\
\hline & Women & 67229 & & $2.2(1.4$ to 3.2$) \dagger$ \\
\hline \multirow[t]{3}{*}{ Chen $^{17}$} & Canadian NPHS & 9149 & 2 years & \\
\hline & Men & 4266 & & 1.0 \\
\hline & Women & 4883 & & $1.9(1.1$ to 3.4$)$ \\
\hline \multirow[t]{3}{*}{ Ford $^{21}$} & NHANES I & 9546 & 10 years & \\
\hline & Men & 3621 & & $1.5(0.9 \text { to } 2.6)^{*}$ \\
\hline & Women & 5925 & & $1.4(1.0 \text { to } 1.9)^{*}$ \\
\hline \multirow[t]{3}{*}{ Gunnbjörnsdóttir ${ }^{18}$} & ECRHS & 16191 & 7.9 yearst & \\
\hline & Men & 7604 & & $2.1(1.4 \text { to } 3.2)^{*}$ \\
\hline & Women & 8587 & & $1.6(1.1 \text { to } 2.1)^{*}$ \\
\hline \multirow[t]{3}{*}{ Huovinen $^{19}$} & Finnish Twin Cohort & 9671 & 9 years & \\
\hline & Men & 4449 & & 3.5 (1.6 to 7.7$)$ \\
\hline & Women & 5222 & & $2.3(0.9$ to 6.1$)$ \\
\hline \multirow[t]{3}{*}{ Nystad ${ }^{16}$} & Norwegian Health Surveys & 135405 & 21 years: & \\
\hline & Men & 66723 & & 1.8 (1.4 to 2.3 ) \\
\hline & Women & 68682 & & 2.0 (1.7 to 2.4$)$ \\
\hline
\end{tabular}

The studies by Camargo et $a l^{14}$ and Romieu et $a l^{20}$ evaluated only women. Table adapted from Beuther and Sutherland. ${ }^{22}$

${ }^{*} \mathrm{OR}$ and $95 \% \mathrm{Cl}$ calculated from primary data. †Reported OR comparing BMI $\geqslant 27$ with the reference BMI category 20.2-21.4. tMean follow-up.

BMI, body mass index; $\mathrm{Cl}$, confidence interval; ECRHS, European Community Respiratory Health Survey; NHANES, National Health and Nutrition Examination Survey; NPHS, National Population Health Survey; OR, odds ratio; RR, relative risk. 


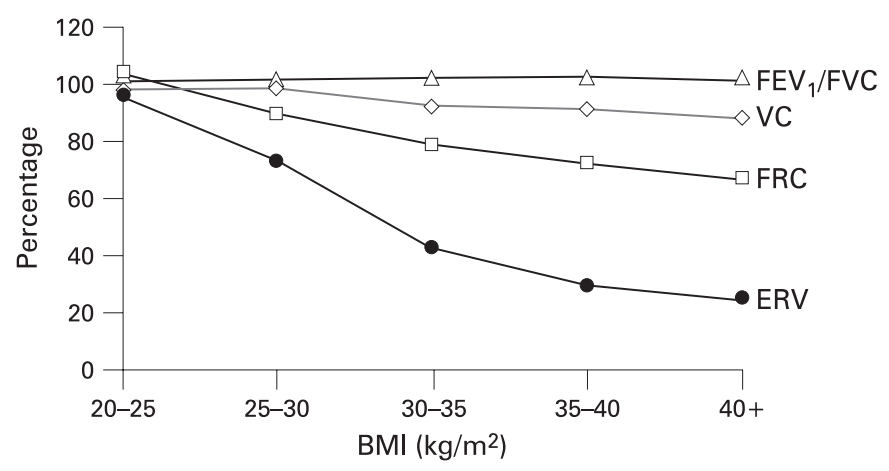

Figure 2 Effect of obesity on lung volumes. ${ }^{38} \mathrm{BMI}$, body mass index; ERV, expiratory reserve volume; $F E V_{1}$, forced expiratory volume in $1 \mathrm{~s}$; FRC, functional residual capacity; FVC, forced vital capacity; VC, vital capacity.

relationship that can be hypothesised in part because of the relationship between obesity, systemic inflammation and metabolic and cardiovascular disorders. ${ }^{29}$ Atopy is an important host factor in the development of asthma, and it has been hypothesised that obesity is associated with an increased likelihood of atopy. To evaluate this relationship, Huang et al studied 1459 eighth-grade students in Taiwan and found that there was a dose-dependent relationship between BMI and the risk of atopy in girls but not in boys. ${ }^{30}$ They also found that the prevalence of AHR increased with increasing BMI, but only in atopic girls, a finding which was later duplicated by Jang et al. ${ }^{31}$ There are, however, some dissenting studies. For example, von Mutius et al (using NHANES III data) failed to find a significant relationship between BMI and atopy among US children aged 3-14 years, although there was a significant relationship between BMI and asthma and between BMI and the use of asthma medications. ${ }^{32}$ Eneli et al found no significant relationship between allergy or hay fever and BMI. ${ }^{33}$ However, in children aged 7-14 years, Schachter et al ${ }^{34}$ found that the risk of atopy increased significantly with BMI only in girls but not in boys, but the relationship was fairly modest in magnitude. Obese girls were also more likely to be wheezy and to complain of a cough than lean girls. In boys the BMI made no difference to these symptoms.

With regard to airway inflammation, Todd et al ${ }^{35}$ studied induced sputum from 727 adults and found that BMI was not significantly associated with increased inflammation in the airways in individuals with or without asthma. McLachlan et $a^{36}$ found that while exhaled nitric oxide levels were raised in those with asthma, there was no significant relationship between either BMI or percentage body fat and exhaled nitric oxide levels. Interestingly, in this study the investigators found that the risk of airflow obstruction and asthma were related to obesity in women but not in men, which could not be explained by differences in airway markers of inflammation. ${ }^{36}$

\section{EFFECTS OF OBESITY ON PULMONARY PHYSIOLOGY}

Obesity adversely impacts lung volumes and is associated with reductions in both forced vital capacity (FVC) and forced expiratory volume in $1 \mathrm{~s}\left(\mathrm{FEV}_{1}\right) \mathrm{r}^{37}$ The impact of obesity on lung volumes has been well studied by Jones and Nzekwu. ${ }^{38}$ They evaluated lung function tests in 373 individuals without lung disease and found that the greatest impact on expiratory reserve volume (ERV) was by raised BMI, with linear declines in ERV with increasing BMI. The ERV of individuals with BMI $>40 \mathrm{~kg} / \mathrm{m}^{2}$ was only $25 \%$ of predicted (fig 2). Vital capacity, total lung capacity, residual volume, and functional residual capacity also fell with increasing BMI, less so than ERV. The FEV 1 to FVC ratio-a robust sign of airflow obstruction-did not change with increasing BMI, indicating that spirometric evidence of restriction (and not obstruction) is a characteristic physiological finding in obesity.

In obesity, reduced lung volumes lead to reduced peripheral airway diameter, a phenomenon which over time perturbs smooth muscle function, ${ }^{39}$ potentially increasing both airway obstruction and AHR. Despite this observation, the clinical data on obesity and AHR are conflicting. In a study of 11277 participants in the European Community Respiratory Health Survey (ECRHS), AHR increased with increasing BMI in men but not women, ${ }^{40}$ and in a case-control study BMI was associated with the development of AHR. ${ }^{41}$ In contrast, Schachter et al showed that, in a group of 1971 adults, BMI was associated with a diagnosis of asthma and symptoms of dyspnoea and wheeze but was not associated with either airflow obstruction or AHR. ${ }^{42}$ Another study of 5984 children showed that obesity was associated with asthma symptoms and inhaler use but not AHR. ${ }^{43}$ Thus, while it is apparent that obesity leads to a number of physiological perturbations that could cause respiratory symptoms, physiological studies do not uniformly support the conclusions that obesity leads to airflow obstruction, AHR or asthma.

Medical and surgical studies of weight loss in individuals with asthma have provided an experimental model system to test the effects of weight loss on lung function and airway inflammation. These studies have shown that weight loss can lead to improvements in both clinical and physiological parameters. In an observational study of 14 obese patients with asthma before and after an 8-week very low calorie diet, weight loss reduced diurnal peak flow variability, increased functional residual capacity and improved measures of airflow limitation. ${ }^{44}$ In a similarly designed 6-month medical weight loss study of 58 obese women (24 of whom had asthma), weight loss improved $\mathrm{FEV}_{1}$ and FVC but did not affect AHR. ${ }^{45}$ Finally, in an experimental study of two groups of 19 patients with obesity and asthma, the group randomised to supervised medical weight loss had improved lung function, asthma symptoms and health status compared with controls. ${ }^{46}$ Similar observations have been made in studies of bariatric surgical patients; severely obese patients who received this surgery experienced improvements in both asthma symptoms and lung function, demonstrating an improvement of approximately $5 \%$ in $\mathrm{FEV}_{1}$ and $8 \%$ in FVC with a $22 \%$ reduction in body weight (from 115 to $89 \mathrm{~kg}$ ). Interestingly, the exhaled nitric oxide concentrations did not change after surgery despite improvements in asthma control and lung function, suggesting that weight loss does not modify lung inflammation. ${ }^{47}$

\section{ROLE OF SEX AND CO-MORBIDITIES IN THE OBESITY/ASTHMA RELATIONSHIP}

It has been hypothesised that variables such as differential expression of sex hormones or body fat distribution may be important in the obesity/asthma relationship as some studies have suggested effect modification of this relationship by sex, with a greater risk of developing asthma in obese women than in obese men. In the ECRHS, Chinn et $a l^{48}$ found that the incidence of asthma over about 9 years of follow-up was approximately $70 \%$ higher in women than in men and 2.2 times higher in the obese subjects $\left(B M I \geqslant 30 \mathrm{~kg} / \mathrm{m}^{2}\right.$ ) than in the nonobese participants. Importantly, whereas obesity was not associated with an increased incident risk of asthma in men, it 
was associated with a nearly threefold increase in the risk in women. ${ }^{48}$ Similarly, using data from the 1970 British Cohort Study, Shaheen et al ${ }^{9}$ showed that BMI was associated with an increased risk of asthma in women but not in men. Luder et al ${ }^{7}$ demonstrated that, in women, the prevalence of asthma was significantly increased in those with a BMI $25 \mathrm{~kg} / \mathrm{m}^{2}$ or higher (BMI 25-27.5: OR 1.76; BMI 27.5-29.9: OR 2.45; BMI $\geqslant 30$ : OR 2.67) compared with the reference category of BMI $22-24.9 \mathrm{~kg} / \mathrm{m}^{2}$. In men the prevalence of asthma was increased in the lowest weight category, BMI $<22 \mathrm{~kg} / \mathrm{m}^{2}(\mathrm{OR} 3.05)$ and in the highest category, $\mathrm{BMI} \geqslant 30 \mathrm{~kg} / \mathrm{m}^{2}$ (OR $2.92,95 \%$ CI 1.39 to 6.14). In one of the few studies to associate body fat distribution and asthma risk prospectively, Romieu et al showed that the transition from a leaner body silhouette to one that was progressively more android (suggesting predominantly abdominal fat distribution) was associated with a substantial increase in asthma risk. ${ }^{20}$ However, despite the suggestion of a differential risk in men and women arising out of individual studies, a meta-analysis by Beuther and Sutherland ${ }^{22}$ found that sex-dependent differences in the strength of the obesity/asthma relationship were abolished when multiple studies were analysed, with a similar effect of body weight on incident asthma in both men and women (OR 1.46 (95\% CI 1.05 to 2.02$)$ vs OR 1.68 (95\% CI 1.45 to 1.94$), p=0.232$ for the comparison). These conflicting data, combined with a need for more work in this area, leave unresolved the precise role of sexspecific variables in modulating the differential asthma risk in women compared with men.

Obesity increases the risk of both gastro-oesophageal reflux disease (GERD) ${ }^{49}$ and sleep disordered breathing (SDB), and at least two epidemiological investigations offer insight into the possible effects of these disorders on the obesity/asthma relationship. In a questionnaire study of over 16000 participants in the ECRHS, Gunnbjornsdottir et al ${ }^{18}$ found that both self-reported GERD symptoms and self-reported asthma symptom onset increased in prevalence with increasing BMI. Despite this, when GERD was controlled for, obesity remained significantly related to the onset of asthma. To address the role of SDB in the obesity/asthma relationship, Sulit et al ${ }^{50}$ studied 788 children and found that, although both SDB and obesity were each independently associated with asthma and wheeze, adjustment for the effect of SDB did not modify the strength of the relationship between obesity and asthma. While there are still many unanswered questions about the interactions among these disorders, these two studies suggest that GERD and SDB do not fully account for the association between obesity and asthma.

From the standpoint of the practising physician, it can be challenging to determine whether respiratory symptoms in obese patients are due to co-morbid asthma or are simply due to altered respiratory mechanics as described above. In the obese patient in whom asthma is suspected, a detailed physiological evaluation which includes not just spirometry but also lung volumes and AHR is warranted to better define the nature and magnitude of the physiological impairment. In addition, alternative causes of dyspnoea related to obesity must be considered, including cardiovascular disease, systemic hypertension with attendant left ventricular diastolic dysfunction, pulmonary hypertension in the setting of obstructive sleep apnoea and/or obesity hypoventilation syndrome. It is also important to consider disorders that can mimic asthma (eg, vocal cord dysfunction), which are often treated with but are unresponsive to systemic glucocorticoids and which paradoxically cause additional weight gain.

\section{EFFECT OF OBESITY ON ASTHMA SEVERITY AND RESPONSE TO} TREATMENT

Studies of the effect of BMI on asthma phenotype typically require more careful characterisation than is feasible in largescale epidemiological studies. Smaller cohorts of asthma patients have increased our understanding in this area, although more research on this aspect of the obesity/asthma relationship is needed. Tantisira et $a^{51}$ analysed data from the Childhood Asthma Management Program in which the asthma phenotype of participants was characterised using impairment domains such as symptoms and lung function, as well as by objective testing for atopy and AHR. They reported the absence of a significant relationship between BMI and asthma control domains such as school absenteeism, emergency department care, requirement for corticosteroids or hospitalisations. While a weak relationship between BMI and exertional cough or wheeze was observed, BMI did not affect eosinophil counts or IgE concentrations and, although there was a weak inverse relationship between BMI and bronchodilator reversibility $(\beta=-0.003$, $p=0.02)$, there was no impact of BMI on AHR. The generalisability of these data is somewhat limited, however, by the observation that most participants were prepubertal and that the median BMI was $17.1 \mathrm{~kg} / \mathrm{m}^{2}$.

It has been hypothesised that obesity is associated with a more severe asthma phenotype, an observation supported in part by data from the TENOR study of individuals with severe asthma, in which the mean BMI in adults was $30.4 \mathrm{~kg} / \mathrm{m}^{2}{ }^{52}$ However, a 2007 report from the Severe Asthma Research Program (SARP) investigators ${ }^{53}$ indicated that obesity was not more prevalent in sever ${ }^{54}$ than in moderate asthma, leading to questions about the role of obesity as a modifier of asthma severity. It is possible, however, that the effects of obesity on prevalent asthma are exerted either through co-morbid illnesses that are associated with asthma or through mechanical effects of obesity on pulmonary physiology.

In obesity, enhancement of normal adipose tissue immune function leads to a systemic inflammatory state, ${ }^{55}$ a phenomenon which is implicated in mediating the metabolic and cardiovascular complications of obesity. ${ }^{56}{ }^{57}$ Interestingly, many of the cytokines found to be elevated in obesity-related systemic inflammation (eg, tumour necrosis factor $\alpha(\mathrm{TNF} \alpha)$ and interleukin 6 (IL6)) are also associated with the development of glucocorticoid insensitivity in asthma. ${ }^{58}$ As noted previously, much of the mechanistic literature evaluating the obesity/ asthma relationship has focused on the role of leptin, which shares structural homology with IL6, regulates T cell proliferation and activation, and recruits and activates monocytes and macrophages. ${ }^{59}$ In mice, exogenous leptin has been shown to enhance AHR and increase serum IgE after inhaled ovalbumin challenge, ${ }^{27}$ suggesting that leptin may have an immunomodulatory role relevant to asthma.

It is not known if systemic inflammation in obesity leads to a reduction in glucocorticoid sensitivity. However, emerging data suggest that there is potential for an interrelationship between inflammation in obesity and glucocorticoid insensitivity in that production of proinflammatory cytokines seen in obesity (TNFa, IL6) are upregulated in lung macrophages from individuals with glucocorticoid-insensitive asthma, ${ }^{60}$ suggesting that the cytokine environment described in obesity may modify the therapeutic response to glucocorticoids. Two post hoc analyses of clinical trial data support this. Peters-Golden et al analysed data from four trials of montelukast and beclometasone and showed that the clinical response (defined by asthma control days) to beclometasone declined as BMI increased. ${ }^{61}$ 
It is also reasonable to speculate that the increased TNF $\alpha$ level in obesity may be relevant to the treatment of obese subjects with asthma. A recent clinical trial showed that the increased expression of membrane-bound $\mathrm{TNF} \alpha, \mathrm{TNF} \alpha$ receptor 1 and $\mathrm{TNF} \alpha$ converting enzyme in peripheral blood mononuclear cells from patients with severe asthma was associated with glucocorticoid insensitivity. ${ }^{54}$ This study also suggested a beneficial effect of the soluble TNF $\alpha$ receptor etanercept in these patients, as shown by improvements in $\mathrm{AHR}, \mathrm{FEV}_{1}$ and asthma-related quality of life, ${ }^{62}$ raising the possibility that controller agents other than corticosteroids may be effective in obese individuals with asthma in whom systemic inflammation and glucocorticoid insensitivity are shown to be important factors.

\section{OBESITY AND SYMPTOMS, HEALTH CARE AND DRUG UTILISATION}

Obese individuals are not only at increased risk of asthma but also more symptomatic, require more asthma drugs and have an increased risk of emergency visits than do lean individuals once they develop asthma. For instance, Sin et a $^{13}$ showed that a BMI of $>31 \mathrm{~kg} / \mathrm{m}^{2}$ increased the risk of asthma by $50 \%$, the use of bronchodilators by $94 \%$ and dyspnoea by 2.7 -fold compared with a normal BMI of $22-25 \mathrm{~kg} / \mathrm{m}^{2}$. Interestingly, in this study the risk of airflow obstruction was no different between the two BMI categories, suggesting that obesity increases asthma symptoms and drug use but has little impact on airways obstruction. These data are consistent with those of Thomson et $a l^{63}$ who showed in a group of subjects with asthma treated in an emergency room that, while obese patients were more likely to be on anti-asthma drugs and had longer stays in the emergency room, they had better peak flows at the time of assessment than did normal weight subjects with asthma. In one of the largest studies to date, Rodrigo and Plaza ${ }^{64}$ showed that patients with increased BMI (mean $29 \mathrm{~kg} / \mathrm{m}^{2}$ ) who presented to emergency rooms with acute exacerbations had higher $\mathrm{FEV}_{1}$ (\% predicted) and peak flows but paradoxically were more symptomatic, taking more corticosteroids and oral theophyllines, and were more likely to be hospitalised than those with a normal BMI. Similar findings have been noted in other studies ${ }^{65}$ and also among children with asthma. ${ }^{66}$

\section{SUMMARY AND CONCLUSIONS}

Robust epidemiological data link obesity with an increased risk of asthma in the community. However, the exact mechanisms responsible for this relationship remain unknown. While animal studies have implicated inflammatory mechanisms as a potential culprit, human studies have not fully endorsed this concept. There is little doubt that obesity adversely impacts lung function, which improves with weight reduction through mechanical unloading, although more information is needed to improve our understanding of how and if obesity modifies phenotype in prevalent asthma. Obesity also increases symptoms and use of medications and health services including emergency rooms and hospitals. Reduction in weight (regardless of method) improves clinical outcomes and enhances lung function, but this is difficult to achieve and even more difficult to sustain.

As we wait for additional studies to further elucidate the relationship between obesity and asthma, the question remains about how best to integrate the current state of knowledge, particularly as it pertains to obese patients in whom the diagnosis of asthma is being considered. It seems reasonable to have heightened clinical suspicion for asthma in obese patients with respiratory symptoms. However, clinical history should be supplemented by careful physical examination and physiological characterisation with complete pulmonary function (not just spirometry) and bronchoprovocation testing to determine if characteristic asthma features such as bronchodilator-responsive expiratory airflow limitation and AHR are present. In addition, common co-morbid illnesses such as heart failure and obesity hypoventilation syndrome should be carefully ruled out. A potentially variable response to asthma treatments (particularly glucocorticoids) related to obesity must also be considered, recognising that a suboptimal response to treatment could also suggest an improper diagnosis. Studies suggest that weight loss reduces symptoms, although the resultant effects on physiological variables such as lung function and biomarkers of airway inflammation and AHR may vary by patient. Notwithstanding these recommendations, there is a pressing need to improve our understanding of the mechanisms underlying the relationship between obesity and asthma and to develop treatment strategies to improve health outcomes of obese patients with asthma.

Funding: Grant support: Canada Research Chair (DDS); NIH HL090982 (ERS)

Competing interests: None.

\section{REFERENCES}

1. World Health Organization. Global strategy on diet, physical activity and health. Geneva: World Health Organization, 2007.

2. Mannino DM, Homa DM, Akinbami LJ, et al. Surveillance for asthma-United States, 1980-1999. MMWR Surveill Summ 2002:51:1-13.

3. Cassol VE, Rizzato TM, Teche SP, et al. Obesity and its relationship with asthma prevalence and severity in adolescents from southern Brazil. J Asthma 2006;43:57-60.

4. Chen $Y$, Dales $R$, Jiang $Y$. The association between obesity and asthma is stronger in nonallergic than allergic adults. Chest 2006;130:890-5.

5. Figueroa-Munoz JI, Chinn S, Rona RJ. Association between obesity and asthma in 4-11 year old children in the UK. Thorax 2001;56:133-7.

6. Kim S, Camargo CA Jr. Sex-race differences in the relationship between obesity and asthma: the behavioral risk factor surveillance system, 2000. Ann Epidemiol 2003;13:666-73.

7. Luder $\mathbf{E}$, Ehrlich RI, Lou WY, et al. Body mass index and the risk of asthma in adults. Respir Med 2004;98:29-37.

8. Santillan AA, Camargo CA. Body mass index and asthma among Mexican adults: the effect of using self-reported vs measured weight and height. Int J Obes Relat Metab Disord 2003;27:1430-3.

9. Shaheen SO, Sterne JA, Montgomery SM, et al. Birth weight, body mass index and asthma in young adults. Thorax 1999;54:396-402.

10. Vlaski E, Stavric K, Isjanovska R, et al. Overweight hypothesis in asthma and eczema in young adolescents. Allergol Immunopathol (Madr) 2006;34:199-205.

11. Young SY, Gunzenhauser JD, Malone KE, et al. Body mass index and asthma in the military population of the northwestern United States. Arch Intern Med 2001;161:1605-11.

12. Ronmark E, Andersson C, Nystrom L, et al. Obesity increases the risk of incident asthma among adults. Eur Respir J 2005;25:282-8.

13. Sin DD, Jones RL, Man SF. Obesity is a risk factor for dyspnea but not for airflow obstruction. Arch Intern Med 2002;162:1477-81.

14. Camargo CA Jr, Weiss ST, Zhang S, et al. Prospective study of body mass index, weight change, and risk of adult-onset asthma in women. Arch Intern Med 1999;159:2582-8.

15. Thomsen SF, Ulrik CS, Kyvik KO, et al. The incidence of asthma in young adults. Chest 2005;127:1928-34.

16. Nystad W, Meyer HE, Nafstad P, et al. Body mass index in relation to adult asthma among 135,000 Norwegian men and women. Am J Epidemiol 2004;160:969-76.

17. Chen $\mathbf{Y}$, Dales $\mathrm{R}$, Tang $\mathrm{M}$, et al. Obesity may increase the incidence of asthma in women but not in men: longitudinal observations from the Canadian National Population Health Surveys. Am J Epidemiol 2002;155:191-7.

18. Gunnbjornsdottir MI, Omenaas E, Gislason T, et al. Obesity and nocturnal gastrooesophageal reflux are related to onset of asthma and respiratory symptoms. Eur Respir J 2004;24:116-21.

19. Huovinen E, Kaprio J, Koskenvuo M. Factors associated to lifestyle and risk of adult onset asthma. Respir Med 2003;97:273-80.

20. Romieu I, Avenel V, Leynaert B, et al. Body mass index, change in body silhouette, and risk of asthma in the E3N cohort study. Am J Epidemiol 2003;158:165-74.

21. Ford ES, Mannino DM, Redd SC, et al. Body mass index and asthma incidence among USA adults. Eur Respir J 2004;24:740-4. 
22. Beuther DA, Sutherland ER. Overweight, obesity, and incident asthma: a metaanalysis of prospective epidemiologic studies. Am J Respir Crit Care Med 2007; 175:661-6

23. Johnston RA, Zhu M, Rivera-Sanchez YM, et al. Allergic airway responses in obese mice. Am J Respir Crit Care Med 2007;176:650-8.

24. Lu FL, Johnston RA, Flynt L, et al. Increased pulmonary responses to acute ozone exposure in obese db/db mice. Am J Physiol Lung Cell Mol Physiol 2006;290:L856-65.

25. Shore SA, Rivera-Sanchez YM, Schwartzman IN, et al. Responses to ozone are increased in obese mice. J Appl Physiol 2003;95:938-45.

26. Shore SA, Johnston RA. Obesity and asthma. Pharmacol Ther 2006:110:83-102

27. Shore SA, Schwartzman IN, Mellema MS, et al. Effect of leptin on allergic airway responses in mice. J Allergy Clin Immunol 2005;115:103-9.

28. Shore SA, Terry RD, Flynt $L$, et al. Adiponectin attenuates allergen-induced airway inflammation and hyperresponsiveness in mice. J Allergy Clin Immunol

2006:118:389-95.

29. Hotamisligil GS. Inflammation and metabolic disorders. Nature 2006;444:860-7.

30. Huang SL, Shiao G, Chou P. Association between body mass index and allergy in teenage girls in Taiwan. Clin Exp Allergy 1999;29:323-9.

31. Jang AS, Lee JH, Park SW, et al. Severe airway hyperresponsiveness in school-aged boys with a high body mass index. Korean J Intern Med 2006:21:10-4.

32. von Mutius E, Schwartz J, Neas LM, et al. Relation of body mass index to asthma and atopy in children: the National Health and Nutrition Examination Study III. Thorax 2001;56:835-8.

33. Eneli IU, Karmaus WK, Davis S, et al. Airway hyperresponsiveness and body mass index: the Child Health and Environment Cohort Study in Hesse, Germany. Pediatr Pulmonol 2006:41:530-7.

34. Schachter LM, Peat JK, Salome CM. Asthma and atopy in overweight children. Thorax 2003;58:1031-5

35. Todd DC, Armstrong S, D'Silva L, et al. Effect of obesity on airway inflammation: a cross-sectional analysis of body mass index and sputum cell counts. Clin Exp Allergy 2007;37:1049-54.

36. McLachlan CR, Poulton R, Car G, et al. Adiposity, asthma, and airway inflammation. J Allergy Clin Immunol 2007;119:634-9

37. Anon. Expert Panel Report 3: Guidelines for the diagnosis and management of asthma. Bethesda, MD: US Department of Health and Human Services; Nationa Institutes of Health; National Heart Lung and Blood Institute; National Asthma Education and Prevention Program, 2007.

38. Jones RL, Nzekwu MM. The effects of body mass index on lung volumes. Chest 2006;130:827-33.

39. Rubinstein I, Zamel N, DuBarry L, et al. Airflow limitation in morbidly obese nonsmoking men. Ann Intern Med 1990;112:828-32.

40. Chinn S, Jarvis D, Burney P. Relation of bronchial responsiveness to body mass index in the ECRHS. European Community Respiratory Health Survey. Thorax 2002; 57:1028-33.

41. Litonjua AA, Sparrow D, Celedon JC, et al. Association of body mass index with the development of methacholine airway hyperresponsiveness in men: the Normative Aging Study. Thorax 2002;57:581-5.

42. Schachter LM, Salome CM, Peat JK, et al. Obesity is a risk for asthma and wheeze but not airway hyperresponsiveness. Thorax 2001;56:4-8

43. Bibi H, Shoseyov D, Feigenbaum D, et al. The relationship between asthma and obesity in children: is it real or a case of over diagnosis? J Asthma 2004:41:403-10.

44. Hakala K, Stenius-Aarniala B, Sovijarvi A. Effects of weight loss on peak flow variability, airways obstruction, and lung volumes in obese patients with asthma. Chest 2000:118:1315-21.

45. Aaron SD, Fergusson D, Dent R, et al. Effect of weight reduction on respiratory function and airway reactivity in obese women. Chest 2004;125:2046-52.
46. Stenius-Aarniala B, Poussa T, Kvarnstrom J, et al. Immediate and long term effects of weight reduction in obese people with asthma: randomised controlled study. BMJ 2000;320:827-32.

47. Maniscalco $\mathbf{M}$, Zedda A, Faraone $\mathbf{S}$, et al. Weight loss and asthma control in severely obese asthmatic females. Respir Med 2008;102:102-8.

48. Chinn S, Downs SH, Anto JM, et al. Incidence of asthma and net change in symptoms in relation to changes in obesity. Eur Respir J 2006:28:763-71.

49. Jacobson BC, Somers SC, Fuchs CS, et al. Body-mass index and symptoms of gastroesophageal reflux in women. N Engl J Med 2006:354:2340-8.

50. Sulit LG, Storfer-Isser A, Rosen CL, et al. Associations of obesity, sleep-disordered breathing, and wheezing in children. Am J Respir Crit Care Med 2005;171:659-64.

51. Tantisira KG, Litonjua AA, Weiss ST, et al. Childhood Asthma Management Program Research Group. Association of body mass with pulmonary function in the Childhood Asthma Management Program (CAMP). Thorax 2003:58:1036-41.

52. Dolan CM, Fraher KE, Bleecker ER, et al. Design and baseline characteristics of the epidemiology and natural history of asthma: Outcomes and Treatment Regimens (TENOR) study: a large cohort of patients with severe or difficult-to-treat asthma. Ann Allergy Asthma Immunol 2004;92:32-9.

53. Wenzel SE, Busse WW. Severe asthma: lessons from the Severe Asthma Research Program. J Allergy Clin Immunol 2007;119:14-21; quiz 22-3.

54. American Thoracic Society. Proceedings of the ATS workshop on refractory asthma: current understanding, recommendations, and unanswered questions. Am J Respir Crit Care Med 2000;162:2341-51

55. Fantuzzi G. Adipose tissue, adipokines, and inflammation. J Allergy Clin Immunol 2005;115:911-9.

56. Weisberg SP, McCann D, Desai M, et al. Obesity is associated with macrophage accumulation in adipose tissue. J Clin Invest 2003:112:1796-808.

57. Wellen KE, Hotamisligil GS. Obesity-induced inflammatory changes in adipose tissue. J Clin Invest 2003:112:1785-8.

58. Webster JC, Oakley RH, Jewell CM, et al. Proinflammatory cytokines regulate human glucocorticoid receptor gene expression and lead to the accumulation of the dominant negative beta isoform: a mechanism for the generation of glucocorticoid resistance. Proc Natl Acad Sci USA 2001;98:6865-70.

59. Sierra-Honigmann MR, Nath AK, Murakami C, et al. Biological action of leptin as an angiogenic factor. Science 1998;281:1683-6.

60. Hauk PJ, Goleva E, Liu AH, et al. Corticosteroid resistant asthma is associated with classical activation of airway macrophages and exposure to lipopolysaccharide. J Allergy Clin Immunol 2006;117:S194.

61. Peters-Golden M, Swern A, Bird SS, et al. Influence of body mass index on the response to asthma controller agents. Eur Respir J 2006:27:495-503.

62. Berry MA, Hargadon B, Shelley M, et al. Evidence of a role of tumor necrosis factor alpha in refractory asthma. N Engl J Med 2006;354:697-708.

63. Thomson CC, Clark S, Camargo CA Jr. Body mass index and asthma severity among adults presenting to the emergency department. Chest 2003;124:795-802.

64. Rodrigo GJ, Plaza V. Body mass index and response to emergency department treatment among adults with severe asthma exacerbations: a prospective cohort study. Chest 2007;132:1513-9.

65. Strine TW, Balluz LS, Ford ES. The associations between smoking, physical inactivity, obesity, and asthma severity in the general US population. J Asthma 2007:44:651-8.

66. Belamarich PF, Luder E, Kattan M, et al. Do obese inner-city children with asthma have more symptoms than nonobese children with asthma? Pediatrics 2000;106:1436-41.

67. Flegal KM, Carroll MD, Ogden CL, et al. Prevalence and trends in obesity among US adults, 1999-2000. JAMA 2002:288:1723-7.

\section{Access the latest content chosen by our Editors}

BMJ Journals editors select an article from each issue to be made free online immediately on publication. Other material is free after 12 months to non-subscribers. Access the Editor's Choice from the home page - or expand your horizons and see what the other BMJ Journals editors have chosen by following the links on any BMJ Journal home page. 